\title{
Perforación aorto-esofágica, diagnóstico clínico e imaginológico: reporte de dos casos clínicos con manejo endovascular
}

\author{
Aorto-esophagic perforation, clinical and imaging diagnosis: report of two \\ cases managed by endovascular technique \\ Elkin Benítez ${ }^{1}$, Martha Alfonso', María Camila Lesmes², Vladimir Barón³, Óscar Hernández 4 , \\ Guillermo Oliveros ${ }^{3}$ \\ 1 Médico, residente de Cirugía General, Universidad del Rosario, Bogotá, D.C., Colombia \\ 2 Médica general, Universidad del Rosario, Bogotá, D.C., Colombia \\ 3 Médico, cirujano general y cirujano vascular, Hospital Universitario Mayor, Bogotá D.C., Colombia \\ 4 Médico, cirujano general y cirujano vascular, Hospital Universitario Mayor, Bogotá, D.C., Colombia
}

\section{Resumen}

La perforación concomitante de esófago y aorta se puede presentar después de la ingestión de cuerpos extraños. El reparo aórtico por técnica endovascular, a pesar de ser reciente, es un tratamiento de primera línea por tratarse de un abordaje poco invasivo, rápido y que permite la estabilización hemodinámica, en comparación con la reparación abierta tradicional.

Se presentan dos casos de perforación aórtica, en los cuales se llevó a cabo el reparo endovascular con éxito. El primer paciente sufrió una ruptura contenida de la aorta torácica, secundaria a la ingestión de un cuerpo extraño (espina de pescado), y presentó mediastinitis. El segundo paciente sufrió una ruptura aórtica en el arco distal a la arteria subclavia, la cual se corrigió por vía endovascular, pero desarrolló una fístula aorto-esofágica y, finalmente, murió.

Palabras clave: aorta torácica; rotura de la aorta; perforación del esófago; aneurisma falso; cuerpo extraño; diagnóstico; procedimientos endovasculares.

\begin{abstract}
Concomitant esophageal and aortic perforation has been described in the literature as major complications of foreign body ingestion. Although it has not been widely studied, aortic endovascular repair is the first line of treatment, for it is less invasive, faster and allows early patient stabilization, as compared with the traditional open repair.
\end{abstract}

Fecha de recibido: 21/03/2018 - Fecha de aceptación: 21/06/2018

Correspondencia: Elkin Benítez, Carrera 45a \#118-87, Bogotá, D.C., Colombia. (57) (301) 790-1377,

Correo electrónico: elkinben@gmail.com

Citar como: Benítez E, Alfonso M, Lesmes MC, Barón V, Hernández O, Oliveros G. Perforación aorto-esofágica, diagnóstico clínico e imaginológico: reporte de dos casos clínicos con manejo endovascular. Rev Colomb Cir. 2019;34:1 90-8. https://doi.org/10.30944/20117582.114

Este es un artículo de acceso abierto bajo una Licencia Creative Commons - BY-NC-ND https://creativecommons.org/licenses/by-nc-nd/4.0/deed.es 
We present two cases managed successfully with endovascular repair of the aortic perforation. The first case had a contained rupture of the thoracic aorta caused by the ingestion of a foreign body (fish bone) and developed mediastinitis. The second case had an aortic rupture in the arc distal to the subclavian artery, managed with endovascular but he developed an aortoesophageal fistula which was finally lethal.

Key words: aorta, thoracic; aortic rupture; esophageal perforation; aneurysm, false; foreign-body; diagnosis; endovascular.

\section{Introducción}

La perforación aórtica es una entidad quirúrgica infrecuente que puede poner en riesgo la vida del paciente, razón por la cual debe ser diagnosticada rápidamente. En muchos casos se presenta como característica típica el dolor torácico, el cual es el signo clínico cardinal del inicio de numerosas enfermedades, algunas con desenlaces fatales; en algunos casos, esto confunde al médico tratante que se enfrenta a este tipo de casos ${ }^{\mathrm{I}}$. Otros síntomas asociados, como la disfagia, la disnea y la odinofagia, pueden orientar el diagnóstico ${ }^{2}$.

La importancia de reconocer la perforación aórtica es hacer un diagnóstico y dar un tratamiento oportuno para evitar complicaciones durante el manejo de esta situación; algunas de las más conocidas son la ulceración de la mucosa esofágica y la inflamación, los abscesos pulmonares, la mediastinitis, la formación de fístulas y la sepsis 3 .

Cuando la anamnesis haga sospechar una enfermedad aórtica torácica, se debe practicar un examen clínico completo y hacer uso de las pruebas de laboratorio disponibles. El paciente debe ser sometido a cirugía de forma inmediata, porque la complicación más temida, la fístula aorto-esofágica con hemorragia masiva, es la primera causa de muerte temprana ${ }^{\mathrm{I}}$.

La perforación aórtica secundaria a cuerpo extraño es poco frecuente. En el presente artículo se reportan dos casos de perforación esofágica y aórtica. En uno de ellos se identificó como causa un cuerpo extraño (espina de pescado) sin formación de fístula aorto-esofágica; en el otro, a pesar de los estudios disponibles, no fue posible descubrir la causa de la lesión aorto-esofágica.
En ambos casos, los pacientes recibieron manejo endovascular temprano.

\section{Caso clínico 1}

Se trata de una paciente de sexo femenino, de 54 años de edad, que ingresó remitida por un cuadro clínico de dolor torácico y epigástrico de nueve días de evolución, irradiado al dorso y de intensidad Io/ıo. Recibió manejo en otra institución por dispepsia y se le estudió con endoscopia de vías digestivas, cuyos resultados estuvieron dentro de límites normales.

Por la persistencia del dolor, se practicó una radiografía de tórax en la que se observó ensanchamiento del mediastino, y una angiotomografía cuyos resultados sugirieron enfermedad aórtica, razón por la cual la paciente fue remitida a nuestra institución. Ingresó con taquicardia, estabilidad hemodinámica y sin otros hallazgos en el examen físico.

Como antecedentes, refirió diabetes mellitus de tipo 2 en tratamiento con medicina alternativa, dos cesáreas y alergia a la penicilina; en la revisión por sistemas, negó haber presentado sangrado digestivo alto o bajo.

En la revisión de la angiotomografía, se encontraron signos sugestivos de ruptura contenida de la pared lateral derecha de la aorta torácica a nivel de la carina, con engrosamiento de las paredes del esófago proximal y pequeño derrame pleural libre bilateral (figura I).

Fue sometida a una corrección endovascular de ruptura aórtica torácica, con endoprótesis recubierta (Medtronic Valiant VAMF2222C ${ }^{150} \mathrm{TE}^{\mathrm{TM}}$ ), la cual se desplegó respetando el orificio de la arteria subclavia izquierda y se logró el cubrimiento exitoso del sitio de ruptura, sin 
evidencia posterior de extravasación con medio de contraste (figura 2).

En el segundo día posoperatorio, persistían la taquicardia y la disnea, sin causa aparente. En un nuevo interrogatorio, la paciente manifestó la ingestión accidental de una espina de pescado con sensación posterior de cuerpo extraño, I2 días antes de iniciarse los síntomas.

Se decidió practicar una nueva angiotomografía torácica con doble contraste, oral y endovenoso, en la que se observó la endoprótesis en la aorta descendente, extravasación del medio de contaste oral por la pared posterior del esófago, neumomediastino y derrame pleural bilateral, lo que confirmaba una perforación esofágica (figura 3).



Figura 1. Angiotomografía torácica con imagen de falso aneurisma y gran hematoma en la aorta torácica descendente

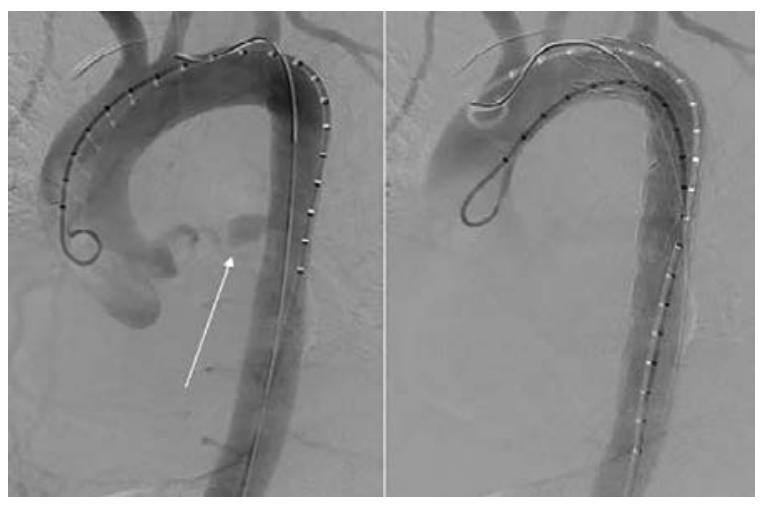

Figura 2. Corrección endovascular de ruptura aórtica torácica, con endoprótesis desplegada por detrás del orificio de la subclavia izquierda, sobre la perforación
Con estos hallazgos, se inició el tratamiento con antibiótico de amplio espectro y se hizo una nueva endoscopia de vías digestivas altas. Esta demostró una solución de continuidad en la pared posterior del esófago medio, con foco de necrosis transmural de $2,5 \mathrm{~cm}^{2}$, a $29 \mathrm{~cm}$ de la arcada dental. Se implantó una endoprótesis recubierta de 120 x $18 \mathrm{~mm}$, en posición adecua$\mathrm{da}$, con su borde proximal a $25 \mathrm{~cm}$ de la arcada dentaria (figura 4).

Inmediatamente después del implante, fue intervenida para drenar el abundante líquido seropurulento del mediastino mediante videotoracoscopia. Se observó la ruptura esofágica posterior de $5 \mathrm{~cm}$, que comprometía el $50 \%$ de la circunferencia, con bordes necróticos y pér-

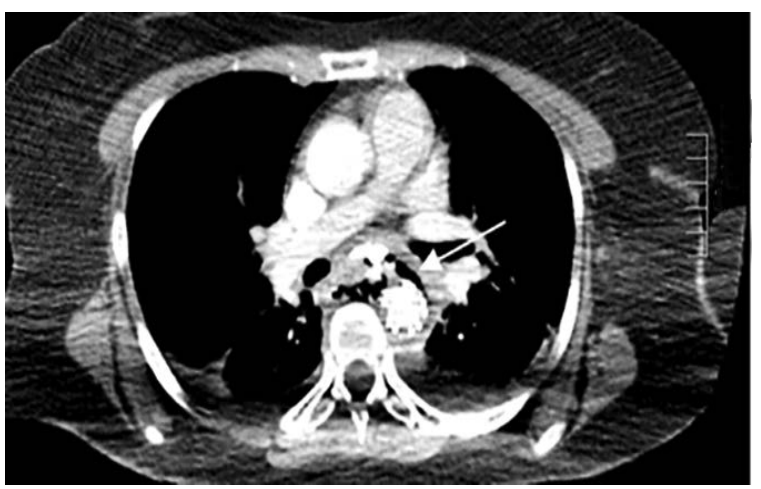

Figura 3. Angiotomografía de tórax con doble contraste: la flecha muestra extravasación de medio de contraste de la pared posterior del esófago y neumomediastino

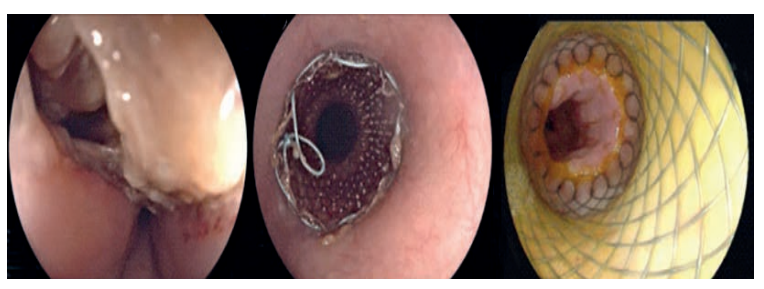

Figura 4. Endoscopia de vías digestivas: solución de continuidad en la pared posterior del esófago medio con foco de necrosis transmural de $2,5 \mathrm{~cm}^{2}$, con colocación de endoprótesis esofágica cubierta 
dida de tejido, y desplazamiento de $2 \mathrm{~cm}$ de la endoprótesis autoexpansible.

Con estos hallazgos, se decidió practicar una toracotomía antero-lateral derecha para desbridar los bordes y reconstruir la pared esofágica con dos colgajos musculares pediculados intercostales (séptimo y octavo) ya que, por el tamaño del defecto y el grado de infección, era imposible la reparación primaria.

Durante su estadía en la unidad de cuidados intensivos, recibió manejo multidisciplinario. En el periodo posoperatorio, se generó una fístula esófago-cutánea organizada hacia la toracostomía derecha, lo cual se documentó en un esofagograma de control.

Durante los 83 días de hospitalización, recibió nutrición entérica por yeyunostomía, se le reacomodó la endoprótesis esofágica y recibió antibioticoterapia contra un microorganismo multirresistente.

Después de su egreso, se cambió la endoprótesis esofágica a una plástica totalmente recubierta (Polyflex Esophageal Stent ${ }^{\mathrm{TM}}$ ), con la cual permaneció por dos meses; toleró la dieta corriente y, en la endoscopia de control, la mucosa esofágica era normal. Seis meses después del egreso, se documentó el cierre completo de la fístula en el esofagograma de control (figura 5, A y B).

Siete meses después de la intervención quirúrgica, ingresó nuevamente por dolor en el epigastrio y el hipocondrio izquierdo, tos, vómito y un episodio de hematemesis. En la tomografía de abdomen se observaron infartos esplénicos y renales bilaterales; en la tomografía de tórax, la endoprótesis estaba en posición, no había fugas, y había leve dilatación del esófago y hallazgos sugestivos de hidroneumotórax tabicado residual.

Se consideró la posibilidad de embolia séptica secundaria a la endoprótesis aórtica, por lo cual se retiró. Durante la cirugía, se halló infección de la prótesis endovascular con aortitis grave y trombos sépticos proximales en la luz. Al retirar la prótesis, se presentó sangrado masivo y la paciente falleció durante la intervención quirúrgica.

\section{Caso clínico 2}

Se trata de una mujer de 79 años de edad, que ingresó al servicio de urgencias por presentar dolor en la región lumbar irradiado al tórax, que se exacerbaba con la actividad, y tos con expectoración hialina, de cinco días de evolución.
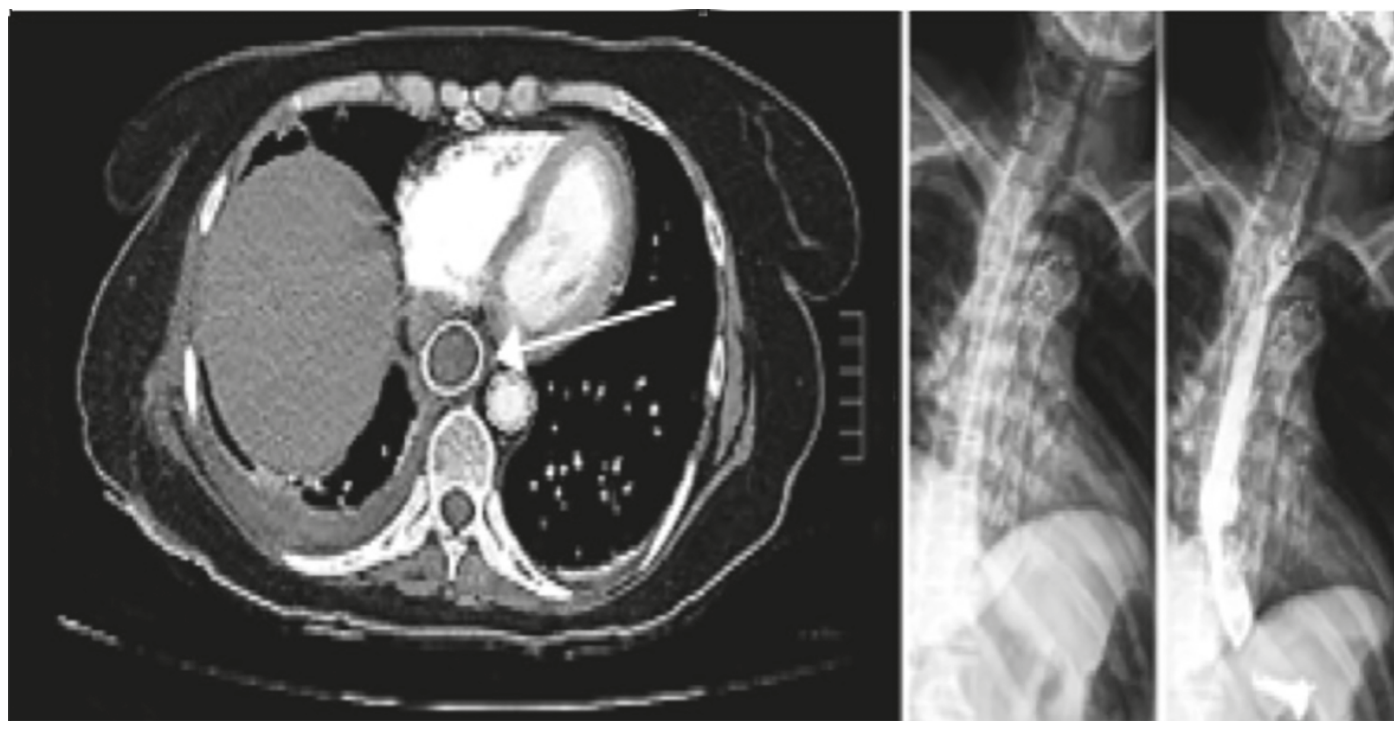

Figura 5. Imágenes de seguimiento. A. Tomografía de tórax que muestra la endoprótesis esofágica. B. Endoprótesis aórtica en adecuada posición, la flecha señala la endoprótesis esofágica. 
Como antecedentes refirió sufrir de hipertensión arterial sistémica, fractura de $\mathrm{L}_{2}$, falla cardiaca y haber sido hospitalizada un mes antes por una neumonía adquirida en la comunidad; recibía tratamiento farmacológico para enfermedades crónicas.

$\mathrm{Al}$ ingresar, se encontraba taquicárdica, normotensa, con desaturación de oxígeno, disminución de los ruidos respiratorios en ambas bases pulmonares y un soplo sistólico; no hubo otros hallazgos de importancia.

Durante la hospitalización, la paciente presentó descompensación hemodinámica con aumento del dolor torácico. Se descartó un proceso coronario agudo y se tomó una angiotomografía de tórax por sospecha de tromboembolia pulmonar; se demostró un aneurisma sacular originado en el cayado aórtico, con signos de ruptura como un hematoma contenido en mediastino superior y ausencia de llenado de la arteria subclavia izquierda (figura 6).

Se decidió hacer una corrección endovascular con una endoprótesis aórtica cubierta (Cook Ze- nith Alpha Thoracic Endovascular Graft $\left.{ }^{\mathrm{TM}}\right)$. Fue necesario cubrir el orificio de la arteria subclavia izquierda, lo cual no produjo complicaciones. La evolución fue satisfactoria y se dio de alta tres días después (figura 7).

Quince días después, la paciente consultó nuevamente al servicio de urgencias por presentar hemoptisis, disnea y deposiciones melénicas. Ingresó taquicárdica e hipotensa con baja perfusión distal. Se diagnosticó choque hipovolémico y se inició reanimación hídrica con hemoderivados; además, requirió asistencia respiratoria y hemodinámica. En la endoscopia de vías digestivas se observó un gran coágulo en el esófago que, al retirarse, dejó ver un defecto en la pared esofágica a $25 \mathrm{~cm}$ de la arcada dental, sugiriendo la presencia de una fístula. Se practicó una angiotomografía de tórax en la que se encontró la endoprótesis en buena posición, aunque había signos de mediastinitis y de neumomediastino masivo (figura 8).

Se decidió someter a la paciente a una toracotomía de urgencia, en la cual se encontró

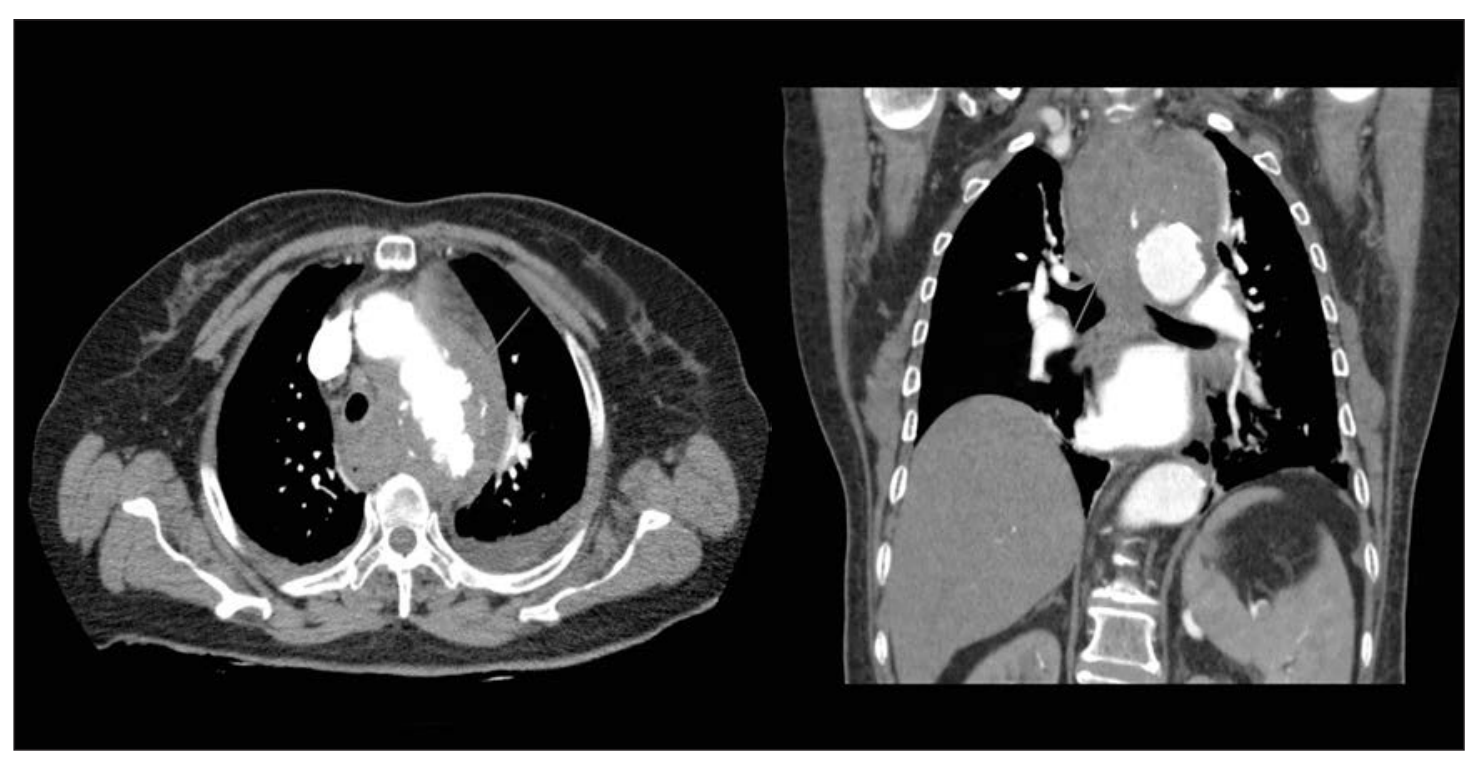

Figura 6. Caso 2. Angiotomografía: úlcera aórtica y gran hematoma mediastinal 

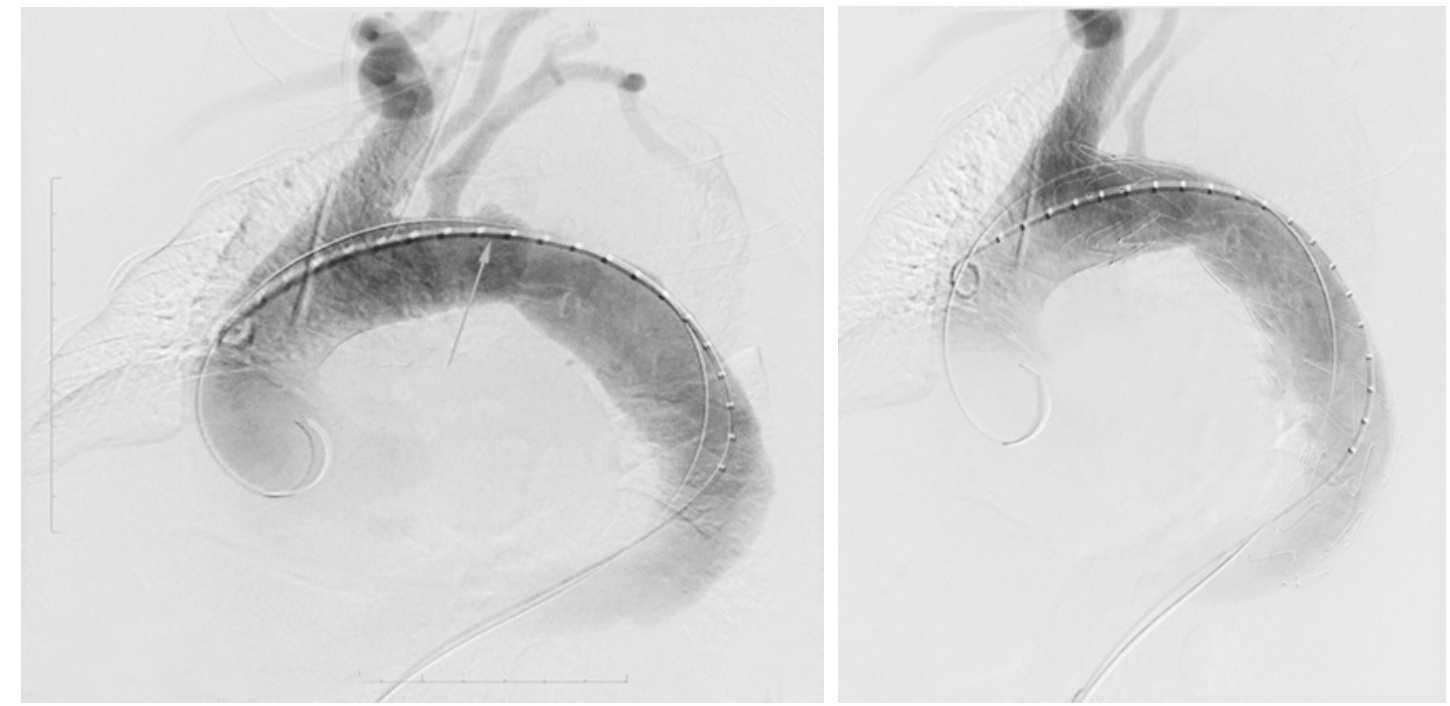

Figura 7. Caso 2. Angiografía previa y posterior a la colocación de la endoprótesis

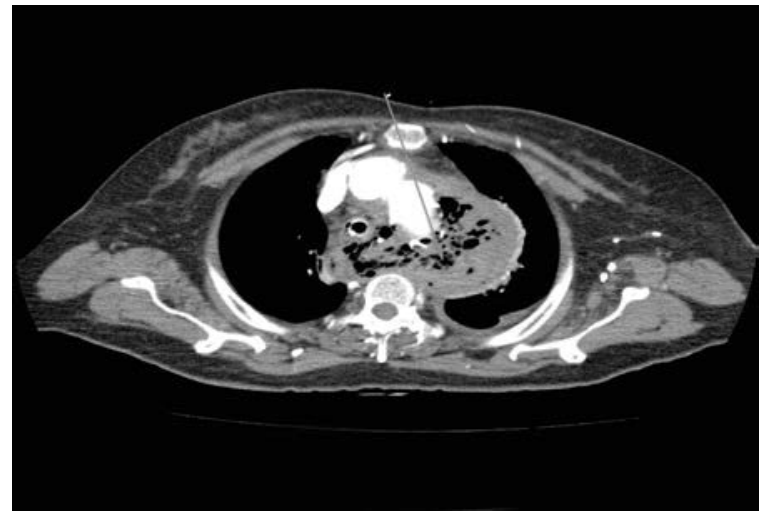

Figura 8. Mediastinitis con neumomediastino masivo

un hematoma en el mediastino posterior, con perforación de $4 \mathrm{~cm}$ en la cara antero-lateral del esófago, por encima de la vena hemiácigos. Por vía endoscópica, se colocó la endoprótesis esofágica recubierta autoexpansible, y tubo de tórax bilateral.

En conjunto, por concepto de cirugía vascular y cirugía cardiovascular, se decidió no practicar ningún procedimiento adicional en este tiempo quirúrgico, debido al gran riesgo de infección de la endoprótesis y muerte. Se inició el cubrimiento con antibióticos de amplio espectro. Continuó en malas condiciones generales, con asistencia respiratoria y hemodinámica, y ocho horas después, presentó asistolia y falleció.

\section{Discusión}

Algunas de las principales complicaciones de la perforación esofágica por cuerpo extraño, son la mediastinitis, la perforación de cualquier tramo del tubo digestivo, la formación de abscesos, la migración del cuerpo extraño a órganos adyacentes y, por último, la formación de fístula aortoesofágica la cual casi siempre es fatal si no es diagnosticada y tratada a tiempo ${ }^{\mathrm{I}, 2}$.

Inicialmente, Ctercteko y Mok informaron en 1980 sobre la reparación esofágica exitosa en un caso de trauma esófago-aórtico por espina de pescado, que fue tratada con pinzamiento cruzado y reparo de la lesión aórtica ${ }^{4}$. Posteriormente, en 1994, Drake, et al., presentaron un estudio sobre el implante de 13 endoprótesis autoexpansibles cubiertas con dacrón en la aorta torácica ${ }^{2}$. Desde entonces, se han informado pocos casos de supervivencia.

El primer manejo endovascular para enfermedades aórticas, lo llevó a cabo Parodi, en I99I, en la aorta abdominal ${ }^{5} \mathrm{y}$ en ese mismo año, Vo- 
lodos, et al., demostraron la posibilidad de hacer implantes de endoprótesis en la aorta torácica.

La perforación esofágica y de la aorta por cuerpo extraño, es una condición que no se reporta frecuentemente ya que, por lo general, es de carácter fatal ${ }^{4,12}$. De todos los pacientes con trauma del tubo digestivo por ingestión de un cuerpo extraño, las lesiones esofágicas corresponden al I2 \% de los casos y, de estas, I a $4 \%$ se presentan con heridas penetrantes $\mathrm{y}, \mathrm{O}, \mathrm{I} 4 \mathrm{a}$ o, $8 \%$, con heridas perforantes, las cuales se asocian con una mortalidad del $22 \%{ }^{6}$. En I,7 a 4,8 \% de los casos de reparación aórtica, pueden presentarse fistulas aorto-esofágicas posquirúrgicas.

En todo paciente que consulte al servicio de urgencias por un cuadro clínico de dolor torácico, se debe hacer una buena anamnesis en busca de antecedentes que nos permitan orientar el diagnóstico y el tratamiento. Si se encuentra el antecedente de ingestión accidental de un cuerpo extraño, se debe descartar inmediatamente su complicación más importante, que es la perforación aórtica. Esto permite hacer los estudios de extensión que sean necesarios, para dar un buen tratamiento a esta entidad. El diagnóstico temprano y la localización de la lesión, pueden contribuir a mejorar el pronóstico vital del paciente ${ }^{7}$. Es por esto que proponemos, además de la radiografía de cuello y tórax, la práctica temprana de una endoscopia de vías digestivas altas y de una tomografía computadorizada con contraste de tórax y abdomen. Entre los aspectos que se deben valorar en estas imágenes, está el sitio habitual de formación de un falso aneurisma secundario a perforación, el cual, en la mayoría de los casos, se produce en el istmo aórtico, punto donde el esófago y la aorta convergen ${ }^{7}$.

Durante el examen físico es muy difícil detectar la presencia de una perforación del tubo digestivo por un cuerpo extraño, razón por la cual se hace necesaria la endoscopia de vías digestivas altas en busca de signos imagenológicos sugestivos de lesión. Sin embargo, en su estudio, Eliashar, et al., concluyen que hay una alta tasa de endoscopias de vías digestivas negativas para lesión esofágica ${ }^{8}$, como ocurrió en nuestro primer paciente, a quien le practicaron un procedimiento endoscópico que no demostró ninguna lesión esofágica. Es por esto que recomendamos el uso de la tomografía computadorizada como examen inicial, el cual presenta una sensibilidad del Ioo \% y una especificidad del $93,7 \%{ }^{8}$.

Entre los años 2005 y 20II, en numerosas series se reportaron pacientes con reparo endoscópico de la perforación, en $95 \%$ de los cuales se logró sellar el defecto aórtico, con una adecuada cicatrización solo en el $77 \%$.

La revisión de las imágenes diagnósticas se debe hacer con un propósito específico. En estos casos, no es primordial visualizar el cuerpo extraño que causa la perforación. Se debe caracterizar la morfología de la aorta en toda su extensión, determinar la presencia o ausencia de fugas, buscar alteraciones en la pared arterial, establecer la presencia o ausencia de hemotórax $\mathrm{y}$, especialmente, determinar si hay lesiones en la aorta descendente, la arteria subclavia o la arteria carótida común, los cuales son los vasos más propensos a ser lesionados ${ }^{6}$.

En el presente informe, ante un signo clínico posterior al procedimiento quirúrgico, en el primer caso se complementaron el diagnóstico y el tratamiento, de forma multidisciplinaria, con exámenes imaginológicos, manejo endoscópico, manejo quirúrgico y cuidados intensivos. En el segundo caso, la revisión de las imágenes de la angiotomografía reveló una clara desviación y compresión extrínseca de la pared esofágica por parte de un hematoma que generó la perforación tardía. Esto permitió y facilitó un proceso infeccioso en el mediastino y la pared aórtica, y, a pesar de contar con la corrección endovascular adecuada, se generó la fístula aorto-esofágica.

En la revisión retrospectiva de las imágenes iniciales de ambos casos clínicos, no hay evidencia de cuerpo extraño, no hay signos evidentes que permitan sospechar que el paciente también cursaba con perforación esofágica; es por esto que ambos pacientes recibieron tratamiento quirúrgico endovascular urgente para la lesión aórtica. 
Se han descrito casos de perforación esofágica hasta dos semanas después de la ingestión de una espina de pescado ${ }^{2}$. En el primer caso, la espina permaneció en el tubo digestivo durante varios días y, posteriormente, presentó manifestaciones clínicas por la perforación de la aorta ascendente a $7 \mathrm{~cm}$ de la subclavia, un tiempo mayor del descrito comúnmente ${ }^{\text {Io. }}$. En el segundo caso, el gran hematoma del mediastino comprimió la pared esofágica, creando un área de isquemia con necrosis posterior que incrementó el tamaño de la perforación inicial.

Con el advenimiento de las técnicas endovasculares para el manejo quirúrgico de la aorta torácica descendente, se cambió considerablemente el pronóstico vital de los pacientes, por tratarse de una cirugía mínimamente invasiva. Este procedimiento consiste en la colocación de una endoprótesis aórtica en el segmento torácico descendente donde se produjo la ruptura. La experiencia exitosa ha probado la seguridad y factibilidad de brindar un tratamiento endovascular inmediato de la ruptura traumática de la aorta torácica mediante endoprótesis recubiertas ${ }^{7}$.

En el estudio de Kubota, et al., se afirma que el tratamiento de todos los pacientes debe ser el reparo endovascular de la aorta torácica (TEVAR), independientemente de que estén hemodinámicamente estables o inestables a su ingreso II. La reparación abierta se asocia con muy alta morbimortalidad (55 a $78 \%$ ) ${ }^{12}$. Por el contrario, el reparo endovascular de la aorta torácica tiene mejores resultados a corto plazo al controlar el sangrado y evitar la pérdida masiva de sangre, aunque se puede asociar con complicaciones graves como la infección del injerto ${ }^{13,14}$.

Se debe tener en cuenta que el éxito de este tipo de procedimientos no solo depende del diagnóstico rápido y certero; también, depende del estado hemodinámico del paciente, su reserva fisiológica, su estado nutricional y el compromiso infeccioso que se encuentre. Es por esto que se recomienda que el tratamiento sea rápido y multidisciplinario. En los dos casos reportados, se usó este concepto y el manejo fue interdisciplinario.
Se han reportado pocos casos de perforación esofágica y aórtica, con mediastinitis secundaria. El tratamiento temprano, endovascular de la aorta, endoscópico y quirúrgico abierto, y mínimamente invasivo de la pared esofágica, puede llegar a ser exitoso. Se han reportado pocos casos en la literatura actual ${ }^{15}$, por lo cual se presentan estas dos pacientes con una condición poco frecuente.

Se concluye que, en los pacientes con cuadros clínicos muy sugestivos de enfermedad aórtica, se debe hacer un manejo interdisciplinario pronto y diligente, lo que disminuirá la morbilidad y la mortalidad, a corto y a largo plazo. El manejo quirúrgico con endoprótesis, a pesar de que ha mostrado resultados diversos, sigue siendo el procedimiento de elección.

Conflicto de interés. Los autores certifican que no tienen conflicto de interés con la publicación del manuscrito.

Fuentes de financiación. Este trabajo fue autofinanciado.

\section{Referencias}

I. Méndez M, Rodríguez M, Ardevol R, Vargas G. Seudoaneurisma de aorta como complicación de una perforación esofágica por una espina de pescado. Semergen. 2013;39:IO4-6. doi: I0.IOI6/j.semerg.20II.I2.004

2. Katsetos MC, Tagbo AC, Lindberg MP, Rosson RS. Esophageal perforation and mediastinitis from fish bone ingestion. South Med J. 2003;96:516-20. doi: I0.I097/OI.SMJ.0000047744.34423.0B

3. Akazawa Y, Watanabe S, Nobukiyo S, Iwatake H, Seki $\mathrm{Y}$, Umehara T, et al. The management of possible fishbone ingestion. Auris Nasus Larynx. 2004;3I:4I3-6.

4. D'Costa H, Bailey F, McGavigan B, George G, Todd B. Perforation of the oesophagus and aorta after eating fish: An unusual cause of chest pain. Emerg Med J. 2003;20:385-6. doi: IO.II36/emj.20.4.385

5. Bush R, Lin P, Lumsden A. Endovascular treatment of the thoracic aorta. Vasc Endovasc Surg. 2003; 37:399405. doi: I0.II77/I5385744030370060

6. Zubar M, Li D, Jabeen S, Fan Q. Endovascular repair in penetrating aortoesophageal foreign body injury. Ann Thoracic Surg. 2013;96:I457-9. doi: doi.org/IO.IOI6/j. athoracsur.20I2.12.046. 
7. Chen A, Yu H, Li HM, Xiao XS, Liu SY. Aortoesophageal fistula and aortic pseudoaneurysm induced by swallowed fish bone: A report of two cases. Cardiovasc Intervent Radiol. 20II;34:Si7-Si9. doi: Io.IO07/soo2700o9-9764-7

8. Eliashar R, Dano I, Dangoor E, Braverman I, Sichel JY. Computed tomography diagnosis of esophageal bone impaction: A prospective study. Ann Otol Rhinol Laryngol. I999;I08:708-IO. doi: IO.II77/00034 8949910800717

9. Herrera A, Freeman RK. The evolution and current utility of esophageal stent placement for the treatment of acute esophageal perforation. Thorac Surg Clin. 2016;26:305-I4. doi: I0.IOI6/j.thorsurg.2016.04.012

Io. Ko S, Lu H, Ng S, Kung C. Fishbone penetration of the thoracic esophagus with prolonged asymptomatic impaction within the aorta. J Vasc Surg. 2013;57:518-20.

II. Kubota S, Shiiya N, Shingu Y, Wakasa S, Ooka T, Tachibana T, et al. Surgical strategy for aortoesophageal fistula en the endovascular era. Gen Thorac Cardiovasc Surg. 2013;6I:560-4. doi: 10.1007/sII748-013-0280-y

I2. Weaver ML, Black JH. Aortobronchial and aortoenteric fistula. Semin Vasc Surg. 20I7;30:85-90. doi: I0.IO53/j. semvascsurg.2017.10.00

I3. Beard J, Gaines P. Loftus I, editors. Vascular and endovascular surgery: A companion to specialist surgical practice. Fifth edition. St. Louis, MO: Elsevier; 2014. p. 408.

I4. Canaud L, Ozdemir BA, Bee WW, Bahia S, Holt P, Thompson M. Thoracic endovascular aortic repair in management of aortoesophageal fistulas. J Vasc Surg. 20I4;59:248-54. doi: IO.IOI6/j.jvs.20I3.07.II7

I5. Kahlberg A, Tshomba Y, Marone EM, Castellano R, Melissano G, Chiesa R. Current results of a combined endovascular and open approach for the treatment of aortoesophageal and aortobronchial fistulae. Ann Vasc Surg. 20I4;28:I782-8. doi: IO.IOI6/j.avsg.20I4.06.003 